\title{
Evaluation of the results of posterior decompression, posterolateral fusion and stabilization by pedicle screw and rod in traumatic thoracolumbar fractures
}

\author{
Islam MA ${ }^{1}$, Sakeb $\mathrm{N}^{1}$, Islam $\mathrm{A}^{1}$, Sarker $\mathrm{SK}^{1}$, Mondol $\mathrm{SK}^{2}$ \\ ${ }^{1}$ Department of Orthopaedic Surgery, Bangabandhu Sheikh Mujib Medical University, Dhaka, \\ ${ }^{2}$ Department of Surgery, Dhaka Medical College, Dhaka.
}

\begin{abstract}
This study is to evaluate the clinical and radiological success of posterior decompression, posterolateral fusion and stabilization by pedicle screw and rod in the management of traumatic thoracolumbar fractures. It is a prospective interventional study which is carried out in Bangabandhu Sheikh Mujib Medical University and different private hospitals in Dhaka city from January 2008 to December 2010. Total 16 patients were selected according to the inclusion and exclusion criteria. There were 10 male patients and 06 female within a age range of 21-40 years. Mean age was 33.32 years. Total 08 cases involved $\mathrm{L}_{1}, 03$ cases involved at $\mathrm{D}_{12}, 02$ cases involved at $\mathrm{D}_{11}$ and at $\mathrm{L}_{2}$ each whereas 01 case at $\mathrm{L}_{3}$. Total 10 cases were of compression fracture and remainder 06 burst fractures. Ten (10) patients presented with paraparesis, 05 patients with incomplete paraplegia and 01 patient with complete paraplegia. All the patients were followed up for minimum 1 year. Patients with paraparesis fully recovered neurologically and could walk without support. All the 05 patients with incomplete paraplegia also recovered fully except 01 which gained partial improvement and walks with aids. One patient with complete paraplegia remained unchanged. Our results show that posterior decompression posterolateral fusion and stabilization by pedicle screw and rod provides a safe and effective surgical option for management of traumatic thoracolumbar fractures.
\end{abstract}

\section{Introduction}

Spinal column injuries represent approximately $3 \%$ of all trauma cases and $10 \%$ of spine injuries ${ }^{1}$. Among the spine injuries $90 \%$ involve the thoracolumbar region ${ }^{2-5}$. Thoracolumbar fractures occurs as a result of axial load on the spinal column after trauma which often causes displacement of the middle column into the vertebral canal and reduces the diameter. Though these types of injuries are best treated by vertebral column decompression and stabilization ${ }^{6}$, management plan differs between many of the researchers regarding operative $^{7,8}$ and non-operative ${ }^{9,10}$ approach.

Thoracolumbar fractures should be managed surgically to protect and improve the neurological function, stabilize the spine, early mobilization and rehabilitation as well as minimizing the pain and subsequent deformity ${ }^{6}$. Open reduction, arthrodesis, and internal fixation offers the possibilities of immediate stability, correction of deformity, early walking and reduced reliance on orthotic containment, with additional theoretical protection against spinal malalignment or neurological injury $^{11,12}$. The most effective treatment for these type of injury is vertebral canal decompression and stabilization of the vertebral column through an anterior approach ${ }^{13,14}$, but the morbidity of this approach is higher than that of posterior pedicle screw approach ${ }^{15,16}$. Over the past two decades, there has been a tendency for posterior stabilization and instrumentation as the preferred treatment modality for thoracolumbar fractures ${ }^{5,6}$.

There are many causes for treatment delay of these fractures, such as the lack of resources in primary care, delay on removing a patient to suitable centers; Multiple trauma patients and vascular problems who need to be treated first, as well as diagnostic failures in primary care ${ }^{17}$. Chadha and Bahadur $^{18}$ considered patients treated with 03 weeks after trauma with the posterior approach. There has been no study of assessing the outcome of surgery through posterior approach within weeks of trauma. The purpose of this paper is to provide a prospective evaluation of patients having traumatic thoracolumbar fractures and to assess the clinical results of patients treated with posterior decompression, postero-lateral fusion and stabilization by pedicle screw and rod. 


\section{Materials and Methods}

This prospective interventonal study is carried out in Bangabandhu Sheikh Mujib Medical University and different private hospitals in Dhaka city from January 2008 to December 2010. Total 16 patients were selected according to the inclusion and exclusion criteria. There were 10 male patients and 06 female within a age range of 21- 40 years. Mean age was 33.32 years. Total 08 cases involved $\mathrm{L}_{1}, 03$ cases involved at $\mathrm{D}_{12}, 02$ cases involved at $\mathrm{D}_{11}$ and at $\mathrm{L}_{2}$ each whereas 01 case at $\mathrm{L}_{3}$. Total 10 cases were of compression fracture and remainder 6 burst fractures. Ten (10) patients presented with paraparesis, 05 patients with incomplete paraplegia and 01 patient with complete paraplegia. The patients operated within 3-20 days after the incident of trauma. Three patients had associated fractures but none of them required surgery. All the patients were followed up for minimum 1 year.

The Inclusion criteria for selection of the study population were i) Denis Type I, II, III thoracolumbar fracture; ii) incomplete neurological deficit; iii) progressive neurological deficit; iv) presented within 03 weeks of trauma. Exclusion criteria were as follows: i) stable fractures; ii) open vertebral fracture; iii) Glasgow coma Scale <14; iv) Denis type IV thoracolumbar fractures. All the cases were evaluated both preoperatively and postoperatively regarding the neurological status clinically and recorded accordingly following the ASIA (American Spinal Injury Association) motor index which is primarily based on Frankel scale as follows.

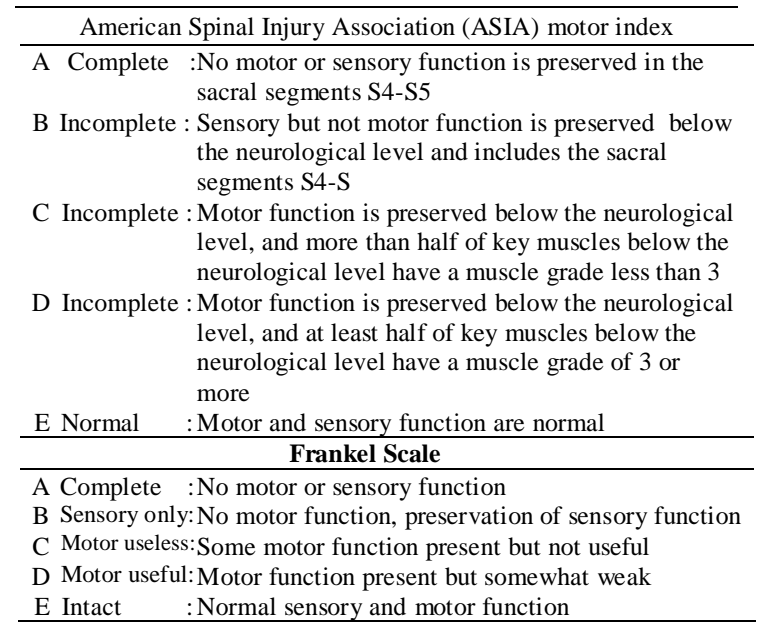

The fracture anatomy was evaluated routinely by X-ray and CT scan. MRI was performed for evaluation of the neural affection. Peroperative difficulty was assessed, the duration of surgery, operative blood loss and postoperative hospital stay was documented. Pain severity was assessed by the Visual Analogue Score (VAS) both preoperative and postoperatively. All the patients were evaluated clinically for minimum one year regarding neurological improvement, functional outcome and complications. The radiological restoration of anatomy was assessed by three different radiologists.

Operative Procedure: Posterior approach is faster and technically simple to carry out and is suitable for emergency conditions. The level of vertebra involved was identified preoperatively by a skin marking under radiological guidance to aid the peroperative vertebral level identification as well as planning of the extent of incision. All the patients underwent surgery under general anesthesia and in prone position. A midline incision was made and extended both proximally and distally according to the requirement. The paraspinal muscles were retracted and the injured level of vertebra identified and confirmed by using $\mathrm{C}$-arm or portable X-ray.

The lamina and the facets were cleared off the soft tissues and any bleeding was secured by proper haemostasis using bipolar diathermy. The pedicles were identified and pedicle screws of adequate length and diameter were inserted two levels above and below the injured segment. The screw placement was rechecked by portable X-ray or Carm. The Titanium rod has been measured, cut and fixed on one side to allow distraction in required situations.

The posterior lamina of the injured vertebra was removed and decompression of the neural elements was approached by removing the unilateral pedicle of the side where the bony fracture fragment caused the compression. The fragments were impacted by a specially designed L-impactor or removed adequately by using specially designed curettes. Dural tears were repaired after repositioning the neural elements whenever found. The decompression was checked and confirmed. The Titanium rods were measured; cut, placed and compression applied. Connector bars were fixed both proximally and distally. The bony fragments cut from the spinous process during the surgery were prepared and placed postero-laterally for postero-lateral fusion. The wound was closed in layers with a drain kept insitu.

\section{Results}

The study comprised of 16 cases during the period of 3 years from January 2008 to December 2010. Table-I demonstrates the demographic variables depicting that, out of 16 patients, $10(62.50 \%)$ were males and 06(37.50\%) were females. Most of the patients $07(43.75 \%)$ were in $26-30$ year age group followed by $05(31.25 \%)$ in $21-25$ year age group. Male to female ratio was 5:3 and the mean age was 30.33 years. 
The cause, level of involvement and perioperative outcome of all the patients under study is elaborated in table-II. Fall was the most common cause of injury $13(81.25 \%)$, remaining $03(18.75 \%)$ were due to road traffic accident. Time between injury and hospital arrival was 3-20 days, mean 14.06 days. X-ray of the thoracolumbar spine was carried out in all patients as well as MRI (100\%), while CT scan was done in $05(31.25 \%$ ) patients. The most common level of injury involved was $\mathrm{L}_{1}$ $08(50 \%)$ followed by $\mathrm{D}_{12} 03(18.75 \%), \mathrm{D}_{11}$ and $\mathrm{L}_{2}$ $02(12.50 \%)$, and $\mathrm{L}_{3}$ involved in one case $01(06.25 \%)$. The commonest type was compression fracture $10(62.50 \%)$ and the remainder was burst fracture 06(37.50\%). Table-II also shows that maximum patients presented with Frankel grade-B, 08(50\%), $6(38.50 \%)$ patients were Frankel grade$\mathrm{C}$ and $01(06.25 \%)$ patient each in grade $\mathrm{A}$ and D. Follow up Frankel grading at one year shows all the patients with grade-C has improved to grade-E. Upto the same functional level of improvement occurred in all patients with grade-B except in 01 case which has improved to grade-D. One patient with grade A did not improve post operatively.

After assessing the fracture type by MRI and CT as shown in figure-I (a) and (b) decompression done posteriorly and stabilization was performed in each case by titanium pedicle screws and rods. The pedicles of above 2 segments and 2 lower segments were approached which is showed in figure-I(c). Postoperative X-ray films showed good hardware position in all patients in the study one example of which showed in figure-I (d),(e). During an average of 14 months (range, 12-36 months) follow-up, no hardware failure was detected. Adequate decompression was achieved in all the cases and no loss of correction was observed. The mean duration of surgery was 03 hours and 44 minutes whereas the mean blood loss was $239 \mathrm{ml}$.

The mean postoperative hospital stay was 05.80 days and all the patients were mobilized in the $1^{\text {st }}$ postoperative day. The preoperative and postoperative pain status was assessed by Visual Analogue Score (VAS). Mean local thoracolumbar back pain at the fracture site was 06.60 (range, 5-9) before operation. Postoperatively, the pain score decreased to 03.20 (range, 2-5) at 3 months, 02.60 (range, 1-4) at 6 months, and 01.60 (range, 0-3) at 12 months. Table- 2 also depicts the preoperative and follow up neurological status showing patients with paraparesis fully recovered neurologically. All the 05 patients with incomplete paraplegia also recovered fully except 01 which gained partial improvement. All these 14 patients could walk independently but the patient with incomplete recovery walks with crutch support. One patient with complete paraplegia did not improve at all.

The post operative complication occurred in only 01 patient which was a superficial wound infection that was managed conservatively and cured. There were 04 cases where dura was found to be injured before operation and repaired during the procedure. No dural injury occurred peroperatively. Associated injuries were found in 02 patients having calcaneal fracture and 01 with stable pelvic fracture which was managed accordingly. The postoperative radiology was assessed by three different radiologists regarding the correction of the sagittal curvature of the spinal column. Correction of $10^{\circ}$ to $15^{\circ}$ of kyphotic angle, mean $12.25^{\circ}$ was achieved postoperatively in I year follow up.

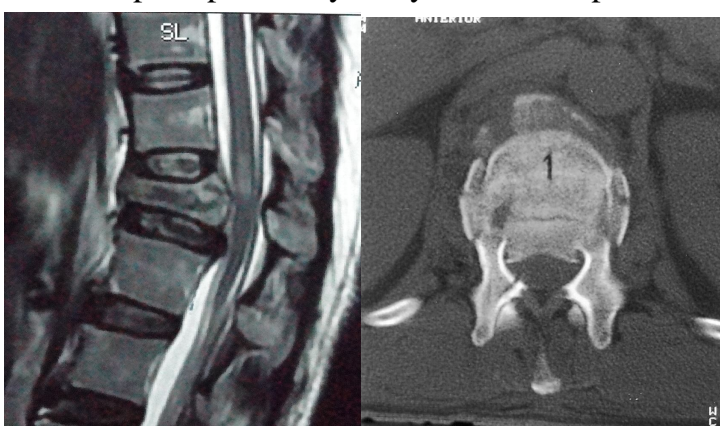

(a)

(b)
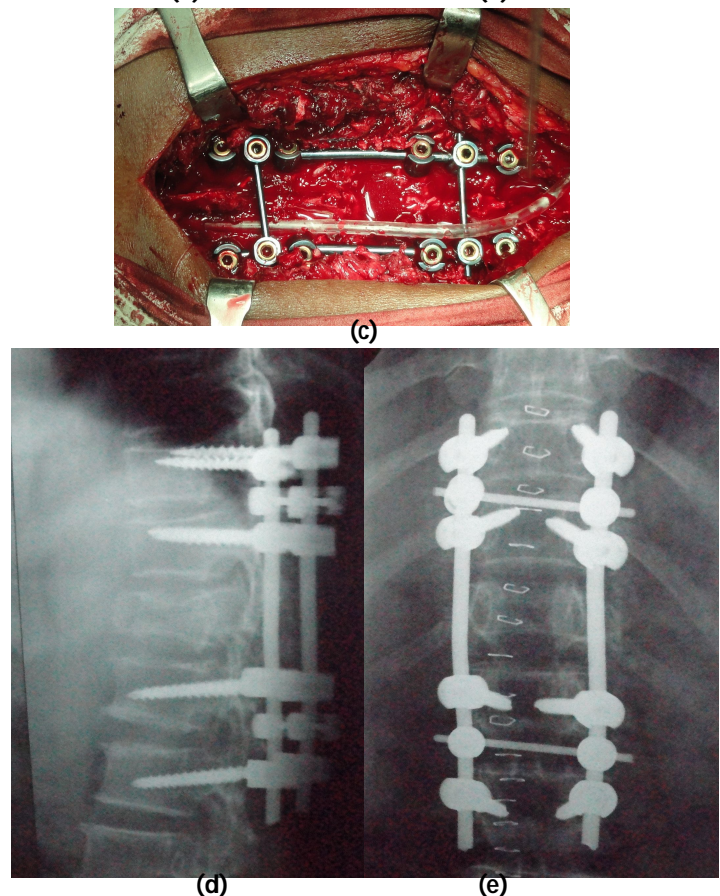

Fig.-1: Case: 10, A 32 years old young male falling from a two storied construction site presenting with incomplete paraplegia due to burst fracture at D12. Preoperative MRI showing a retropulsed fragment compressing over the neural elements of the spinal canal with reduced diameter of the canal (a), Preoperative CT scan assessment of the compromised spinal canal (b), Preoperative view showing the pedicle screw and rod with transverse bar fixation (c). Postoperative X-ray showing satisfactory placement of pedicle screws and correction of kyphotic deformity (d),(e). Table I: Demographic variables of study population $(n=16)$. 


\begin{tabular}{llllc}
\hline Range of Age & Number & $\begin{array}{c}\text { Percentage } \\
(\%)\end{array}$ & $\begin{array}{l}\text { Male } \\
(\%)\end{array}$ & $\begin{array}{c}\text { Female } \\
(\%)\end{array}$ \\
\hline $21-25$ & 05 & 31.25 & $02(12.50)$ & $03(18.75)$ \\
$26-30$ & 07 & 43.75 & $05(31.25)$ & $02(12.50)$ \\
$31-35$ & 03 & 18.75 & $02(12.50)$ & $01(06.25)$ \\
$36-40$ & 01 & 06.25 & $01(06.25)$ & $00(00.00)$ \\
\hline Total & 16 & 100 & $10(62.50)$ & $06(37.50)$ \\
\hline
\end{tabular}

Table II: Level of involvement, cause and postoperative neurological and pain status $(n=16)$.

\begin{tabular}{llllccc}
\hline $\begin{array}{l}\text { Case } \\
\text { no }\end{array}$ & $\begin{array}{l}\text { Level (Type) } \\
\text { of involvement }\end{array}$ & $\begin{array}{l}\text { Cause of } \\
\text { fracture }\end{array}$ & $\begin{array}{c}\text { Frankels grade } \\
\text { Pre } \\
\text { operative }\end{array}$ & $\begin{array}{c}\text { Visual } \\
\text { Post } \\
\text { operative } \\
\text { (1 year) }\end{array}$ & $\begin{array}{c}\text { ancogue score(VAS) } \\
\text { Post }\end{array}$ & $\begin{array}{c}\text { Post } \\
\text { operative } \\
\text { operative } \\
\text { (1 year) }\end{array}$ \\
\hline 01 & L1 (Comp.) & Fall & C & E & 08 & 02 \\
02 & D12 (Burst) & Fall & B & D & 09 & 02 \\
03 & L1 (Comp.) & Fall & B & E & 07 & 01 \\
04 & L1 (Comp.) & Fall & C & E & 06 & 01 \\
05 & D12 (Comp.) & RTA & B & E & 08 & 02 \\
06 & L3 (Burst) & Fall & B & E & 07 & 03 \\
07 & D11 (Comp.) & Fall & A & A & 00 & 00 \\
08 & L1 (Comp.) & RTA & C & E & 08 & 01 \\
09 & L2 (Comp.) & Fall & D & E & 05 & 01 \\
10 & D12 (Burst) & Fall & B & E & 06 & 02 \\
11 & L1 (Burst) & Fall & B & E & 07 & 01 \\
12 & L1 (Comp.) & Fall & B & E & 08 & 03 \\
13 & L1 (Burst) & Fall & C & E & 06 & 02 \\
14 & L2 (Comp.) & RTA & C & E & 06 & 03 \\
15 & D11(Comp.) & Fall & C & E & 07 & 01 \\
16 & L1 (Burst) & Fall & B & E & 08 & 01 \\
\hline
\end{tabular}

\section{Discussion}

Majority of patients in our study were young. The mean age was around thirty years. It is clear from many studies that young people suffer spinal cord injuries more often than any other age group. Out of 16 cases, $10(62.50 \%)$ were male and 06 $(37.50 \%)$ females. Raja RA showed $86 \%$ male patients in his series of 50 patients $^{6}$, similarly in other studies males are supposed to be more exposed to trauma than females ${ }^{19,20}$. Fall was the most common cause of injury in $13(81.25 \%)$ cases which has also been observed in some studies ${ }^{6,19}$, but Payer $M$ showed road traffic accident is the common cause of injury ${ }^{16}$.

Hyperflexion and axial loading was the common mode of injury observed. Most common level involved was $\mathrm{L}_{1}(50 \%)$ followed by $\mathrm{D}_{12}(18.75 \%)$. Raja RA showed $46 \%$ involvement of $\mathrm{L}_{1}$ and $12 \%$ involvement of $\mathrm{D}_{12}$ coinciding with our results ${ }^{6}$, other studies Shah AA et al, McCormack B et al and Hitchon PW et al also showed the common level of injury is $\mathrm{D}_{12}-\mathrm{L}_{1}{ }^{19-21}$. Compression fracture was the most common fracture Found (62.50\%) followed by burst fracture $(37.50 \%)$. Most common grade found in both types of fractures was Frankel grade-B. It was also noted that more severe the canal compromise, worse the neurological deficit. Gerzbein and Hitchon also showed the similar scenario $^{22}$.

With the advent of modern design and appliances transpedicular screw fixation by a dorsal approach offers a fast, stable and safe means of achieving stabilization and correcting malalignments ${ }^{23}$. In our study all the postoperative follow up X-ray has been evaluated by three radiologists with an interpretation of good alignment repositioning and restoration of the spinal column and postoperative correction of kyphotic deformity. We have shown that good restoration of the sagittal curve is possible without loss of correction during the healing of the fracture. We have achieved postoperative correction of $10^{\circ}$ to $15^{\circ}$ of kyphotic angle, mean $12.25^{\circ}$. Essess SI et al showed $11.3^{\circ}$ correction which is comparable to our result. ${ }^{11}$ Many other studies also demonstrated the successful repositioning, kyphosis correction, reliable fracture consolidation and neural decompression as well as good neurological recovery achieved via the dorsal approach ${ }^{24}$, although Verlan JJ et al concluded that no treatment is able to restore the morphology of the vertebral segment to normal physiological levels for thoracolumbar spine fractures ${ }^{25}$.

In our study only one case developed superficial wound infection which was managed conservatively. Herck BV et al also showed two complications in his series of 30 cases $^{26}$. Hospital stay was short which is compatible with the study performed by McLain RF et $\mathrm{al}^{27}$. Rehabilitation in terms of physiotherapy was started in wards and continued by authors themselves. The average level of discomfort, according to the visual-analog pain scale at the final follow-up evaluation was relatively low as in other studies ${ }^{27,28}$. Out of the 16 patients $14(87.50 \%)$ had complete recovery within 1 year of follow up. One $(06.25 \%)$ patient had partial recovery needing walking aids whereas another one had no recovery of functions and was bed ridden. Avanzi $\mathrm{O}$ studied on 15 patients treated within 3-5 weeks of the trauma found improvement of the neurological picture in $60 \%$ of their patients $^{29}$. Out of the 14 patients who had complete recovery in our series $07(45.25 \%$ ) patients could return to his previous work. Wood $\mathrm{K}$ et al found $42 \%$ patients returning to their previous work and Kraemer WJ found 33\%, which are almost similar to our studies ${ }^{2,24}$.

There are limitations of our study as the study population is small and period of follow up of only a year. We also could not determine whether posterior decompression clears the canal adequately as the computed tomography scans were not performed postoperatively. Only the functional improvement and radiological alignment were considered and no co-morbid factors were evaluated regarding the outcome of the surgery.

Conclusion: Posterior decompression and instrumentation provides a safe and effective 
surgical option for management of traumatic thoracolumbar fractures. It effectively decompresses the canal, achieves better anatomic restoration and correction of kyphotic deformity. Early pain relief ensures early mobilization and rapid recovery.

\section{References}

1. Lukas R, Suchomel P, Sram J. Surgical treatment of thoracolumbar spine fractures. Coluna/columna 2006; 5(2): 84-89.

2. Kraemer WJ, Schemitsch EH, Lever J, McBroom RJ, McKee MD, Waddell JP. Functional outcome of thoracolumbar burst fractures without neurological deficit. J Orthop Trauma 1996; 10(8): 541-4.

3. Esses SI, Botsford DJ, Kostuik JP. Evaluation of surgical treatment for burst fractures. Spine 1990; 15(7): 667-73.

4. Denis F. The three column spine and its significance in the classification of acute thoracolumbar spinal injuries. Spine 1983; 8(8): 817-31.

5. Muller U, Berlemann U, Sledge J, Schwarzenbach O. Treatment of thoracolumbar burst fractures without neurologic deficit by indirect reduction and posterior instrumentation: bisegmental stabilization with monosegmental fusion. Eur Spine J 1999; 8(4): 284-9.

6. Raja RA. Management of thoracolumbar spine injuries at a tertiary care hospital. J Ayub Med Coll Abbottabad 2010; 22(1): 171-5

7. Jacobs RR, Nordwall A, Nachemson A. Reduction, stability, and strength provided by internal fixation systems for thoracolumbar spinal injuries. Clin Orthop Relat Res 1982; 171: 300-8.

8. McCullen G, Vaccaro AR, Garfin SR. Thoracic and lumbar trauma: rationale for selecting the appropriate fusion technique. Orthop Clin North Am 1998; 29(4): $813-28$

9. Willen J, Lindahl S, Nordwall A. Unstable thoracolumbar fractures. A comparative clinical study of conservative treatment and Harrington instrumentation. Spine 1985; 10(2): 111-22.

10. Cantor JB, Lebwohl NH, Garvey T, Eismont FJ. Nonoperative management of stable thoracolumbar burst fractures with early ambulation and bracing. Spine 1993; 18(8): 971-6.

11. Esses SI. The placement and treatment of thoracolumbar spine fractures. An algo-rithmic approach. Orthop Rev 1988; 17(6):571-84.

12. Akalm S, Kis M, Benli IT, Citak M, Mumcu EF, Tuzuner M. Results of the AO spinal internal fixator in the surgical treatment of thoracolumbar burst fractures. Eur Spine J 1994; 3(2): 102-6.

13. Kaneda K, Abumi K, Fujiya M Burst fractures with neurologic deficits of thoracolumbar-lumbar spine. Results of anterior decompression and stabilization with anterior instrumentation. Spine 1984; 9: 788-95.

14. Kaneda K, Taneichi H, Abumi K, Hashimoto T, Satoh S, Fujiya M. Anterior decompression and stabilization with kaneda device for thoracolumbar burst fracture associated with neurologic deficits. J Bone and Joint Surg Am 1997; 19: 69-84.
15. Korovessis P, Baikousis A, Zacharatos S, Petsinis G, Koureas G, Ililopoulus P. Combined anterior plus posterior stabilization versus posterior short segment instrumentation and fusion for mid-lumbar (L2-L4) burst fractures. Spine 2006; 31: 859-68.

16. Payer M. Unstable burst fractures of the thoracolumbar junction: treatment by posterior bisegmental correction/fixation and staged anterior corpectomy and titanium cage implantation. Acta Neurochir (Wien) 2006; 148: 299-306.

17. Reid DC, Henderson R, Saboe L, Miller JD. Etiology and clinical course of missed spine fractures. J Trauma. 1987; 27: 980-6.

18. Chadha M, Bahadur R. Steffee variable screw placement system in the management of unstable thoracolumbar fractures: a Third World experience. Injury 1998; 29: 737-42.

19. Shah AA, Memon IA. Antero-lateral decompression for traumatic spinal cord compression. J Pak Med Assoc 1994; 44(10): 242-3.

20. Hitchon PW, Torner JC, Hadded SS, Follett KA. Thoracic and lumbar fractures. Management analysis. In: Hitchon, Traynelis, Rengachary, Techniques in spinal fusion and stabilization. New York: Thieme Medical Publishers 1995; 338-44

21. McCormack B, Mac Millan M, Fessler RG Management of thoracic, lumbar and sacral injuries. In: Tindall Gt, Cooper PR, Barrow DL. (Editors). Practice of Neuro-surgery. Vol II. Baltimore: William and Wilkins; 1996; 1721-8.

22. Gertzben SD, Court Brown CM, Marks P, et al. The neurologic outcome following surgery for spinal fractures. Spine 1988; 13(6): 641-4.

23. Wood K, Bohn D, Mehbod A. Anterior versus posterior treatment of stable thoracolumbar burst fractures without neurologic deficit: a prospective, randomized study. J Spinal Disord Tech 2005; 18(Suppl.): S15-S23.

24. Oertel J, Niendorf WR, Darwish N, Schroeder HW, Gaab MR.. Limitations of dorsal transpedicular stabilization in unstable fractures of the lower thoracic and lumbar spine: an analysis of 133 patients. Acta Neurochir (Wien) 2004; 146(8): 771-7.

25. Verlaan JJ, Diekerhof CH, Buskens E, et al. Surgical treatment of traumatic fractures of the thoracic and lumbar spine: a systematic review of the literature on technique, complications, and outcome. Spine 2004; 29: 803-14

26. Herck BV, Leirs G, Loon JV. Transpedicular bone grafting as a supplement to posterior pedicle screw instrumentation in thoracolumbar burst fractures. Acta Orthopaedica Belg 2009; 75: 815-21.

27. McLain RF, Sparling E, Benson DR. Early failure of shortsegment pedicle instrumentation for thoracolumbar fractures. A preliminary report. J Bone Joint Surg Am 1993; 75(2): 162-7.

28. McEvoy RD, Bradford DS. The management of burst fractures of the thoracic and lumbar spine. Experience in 53 patients. Spine 1985; 10(7): 631-7.

29. Roberson JR, Whitesides TE Jr. Surgical reconstruction of late post-traumatic thoracolumbar kyphosis. Spine 1985; 10: 307-11. 